\section{An Electric Harp}

By F. H. Williamson, Jr.

$\mathrm{B}^{\mathrm{EING} \text { possessed of a three-bar auto-harp, of which }}$ $\mathrm{B}_{\text {the bar mechanisn had been accidentally broken, it }}$ occurred to me that it might be arranged to be played by electric power.

My first intention was to have pickers for the strings as in a regular harp, but this scheme was abandoned, as too complicated, an arrangement for striking blows upon the strings, being substituted. Some experiments showed that the simplest plan was to use solenoids, that is, magnet coils with movable iron cores. How this was managed and the apparatus constructed, is shown in the accompanying illustrations.

Upon the harp $A$ (Fig. 1) were screwed two upright side pieces $B$ and $B^{\prime}$ with foot pieces $C$ and $C^{\prime}$ to support the instrument in inverted position for play-

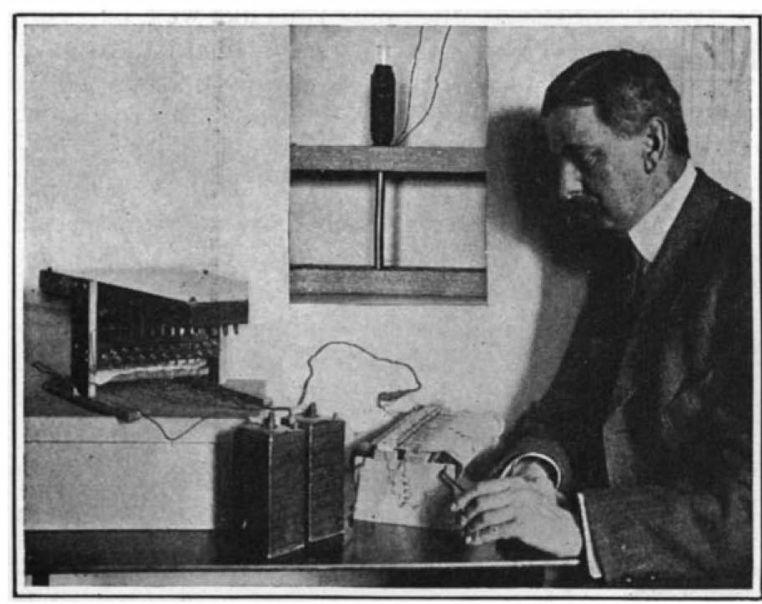

The electric harp in operation. A solenoid shown

in the insert.

ing. Three strips, $D, G$, and $I$, of $3 / 8$ th stuff, $1 \frac{112}{2}$ inches wide, were then cut out. The strip $D$ was laid across the 21 strings of the harp, between the two uprights, and carefully marked where the strings crossed it. These marks were extended to the $11 / 2$-inch side, cross ing two parallel lines drawn lengthwise on the strip, $1 / 2$ an inch apart. A light mark was then made in the wood, with a center punch, at alternate points where the cross lines joined the parallel lines, "staggering" them, as it is called. At each mark, a $3 / 16$-inch hole was then drilled perpendicularly through the wood, using a twist drill.

The solenoid coils were now wound upon 21 pieces of $3 / 16$-inch thin glass tube, 2 inches long, the glass . being nicked with a file and broken between the fingers. The winding was done thus: A bit of $1 / 8$-inch brass rod 3 inches long was clamped in a vise, and one of the tubes slid upon it. A wooden crank was then forced temporarily on the glass, and the latter wound with four layers of No. 24 enameled copper wire, in a coil $11 / 2$ inches long. The terminals were twisted together and the ends of the coils shellacked to prevent their slipping.

The free ends of the tubes were then set in the drilled holes in the wooden strip $D$, and glued securely, after which the strip was secured between the uprights, in such a position, that the ends of the solenoid tubes $E^{1}, E^{2}$, etc., were one half inch from the harp strings, which show in the figure as a row of dots. One terminal of each coil was then scraped free of enamel and soldered to a common return wire $F$, terminating in a screw and washer on one of the side pieces, for a battery connection.

The strip $G$ was then screwed between the uprights, close to, and at right angles with, the strip $D$. It was drilled to receive 21 round head No. 6 brass screws, one inch long, provided with washers. The screws were set in opposite sides of the strip, alternately, similar

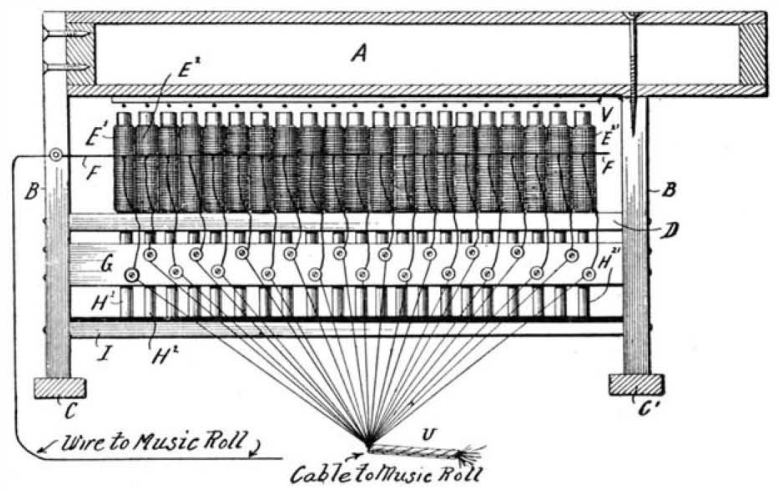

Fig. 1.-Front view of solenoids.

to the solenoids. The iron cores for the magnets were made from 3-inch wire nails of a size to just slip easily into the tubes. The heads were cut off, and both ends were filed flat, reducing the length to $2 \frac{1}{2}$ inches. They were then set in place in the tubes, as shown at $H^{1}, H^{2}$, etc., and the strip $I$ upon which they were to rest, was secured between the supports, 2 inches below the strip
$D$, so that $1 / 2$ inch of the core remained in the tubes. The upper face of the strip $I$ was padded with a fourfold thickness of canton fiannel, to reduce the noise of the dropping cores. A similar strip of flannel $(V)$ wa glued to the face of the harp, opposite the solenoids, to cut down the reverberation of the strings.

The keyboard and music roll attachment, shown in Fig. 3, consisted of a base board $J, 13$ inches long with upright sides $K, K^{\prime}, 5$ inches high. The rollers, $L, L^{1}$ were made of 12-inch lengths of 2-inch curtain pole, with $21 / 2$-inch heads $M, M^{1}$, etc., turned from cigar bo wood. They were pivotted at one end, on wire nails, driven into the centers; and revolving in holes drilled in the side piece. In the other ends were forced 2 -inch cranks of 3/16-inch round brass rod $N, N^{1}$, revolving in open slots in the side piece to allow the rollers to be easily removed. The slots were covered with small brass strips which could be turned aside to release the

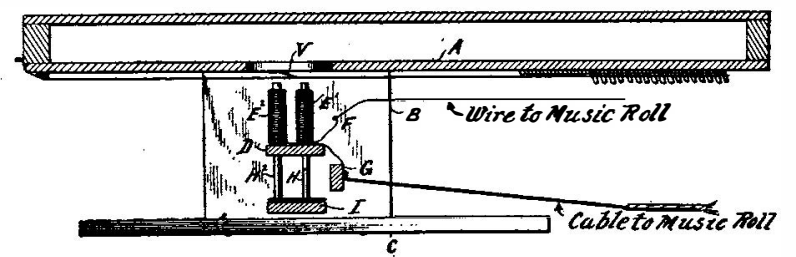

Fig. 2.-End view of solenoids.

rolls. A cross strip, marked $O$, was fastened to the top of the side pieces, just back of the front roller, and to this was secured a strip $(P)$ of $1 / 16$-inch brass $3 / 8$ inch wide provided at one end with a screw and washer for the battery connection.

Half an inch back of strip $O$ was placed a second cross-piece $Q$, of the same size as the former, but raised $1 / 2$ inch above it, on small blocks. One end of strip $Q$ was hinged to the block and the other held down by the latch $\mathbb{S}$. To the narrow edge of this strip were screwed 22 strips of light spring brass $R^{1}, R^{2}$, etc., $11 / 4$ inches long and tapering from $1 / 4$ inch wide at the large en to $1 / 16$ inch at the small end. The strips were clampe together in a vise, and drilled through the wide end in one operation with a hole large enough to take a No. 6 screw. The extreme tips of the narrow end were turned up slightly to avoid catching in the music roll, and the whole set fastened by screws to the strip $Q$ in such position that the small ends pressed firmly upo the cross-strip $P$, and were spaced just $1 / 2$ inch apart. The paper music was made from a strip of heav wrapping paper, about 6 feet long by 12 inches wide. One end was cut V-shaped, the point being tacked to the center of the front roller, which was then turned over a couple of times to hold the paper firmly. The paper was then wound forward under the springs, and the notes and chords marked in pencil in a line with the corresponding springs. The bar $Q$ was then thrown back out of the way and a strip of wood, sawed across the grain, was set temporarily beneath the paper at this point. This wood was 12 inches wide and 514 inches high, and was used as a support upon which the holes were punched in the paper at each pencil mark, using a hollow steel punch of $3 / 8$ inch diameter. The en grain of the wood allowed the punch to sink in, making a clean, round hole. Perforation for successive notes were spaced $1 / 2$ inch apart. The harp and keyboard were connected with No. 24 enameled wire, as the distance between them was only about 18 inches. For longer distance No. 18 or 20 wire would be required. A wire was connected to screw No. 1 on the cross-piece $D$, Fig. 1, and the other end to the screw on spring No. of the keyboard. No. 2 screw on the harp was joined to spring No. 2 with a second wire, and so on. The wires were then gathered into a cable $U$ and taped together as shown. A battery of two or three dry cells was attached, one terminal going to the screw on the common return wire $F$ and the other to the screw on the strip $P$.

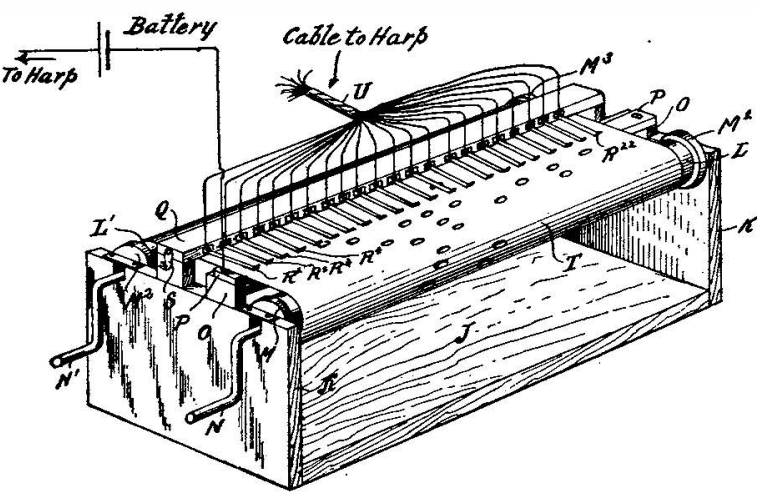

Fig. 3.-Music roll mechanism.

To operate the harp the crank of the front roller was turned to draw the paper forward, and as the perforations in the latter reached the various springs, they dropped down into contact with the strip below, throwing the current into the corresponding solenoids and drawing up the iron cores so that they struck the strings with a clear, sharp blow, dropping instantly as the paper was drawn forward, and the current shut off. The best average speed for the roll was found to be about two longitudinal feet per minute.

\section{A Simple Vehicle Jack \\ By James H. Armstrong}

NE of the simplest forms of jacks for use in liftne bodies of wagons or other vehicles is illustrated in the accompanying drawing. The device can readily be made by any amateur and the construction is inexpensive. The uprights of the jack consist of a single length of iron $1 \frac{1}{4}$ by $1 / 2$ inch, bent double or to hairpin form, with the lower ends secured in a block of wood measuring 2 by 6 inches. The ends of the uprights are fixed into receses in the block, and are dicated by dotted lines in the drawing. The lever on which the vehicle

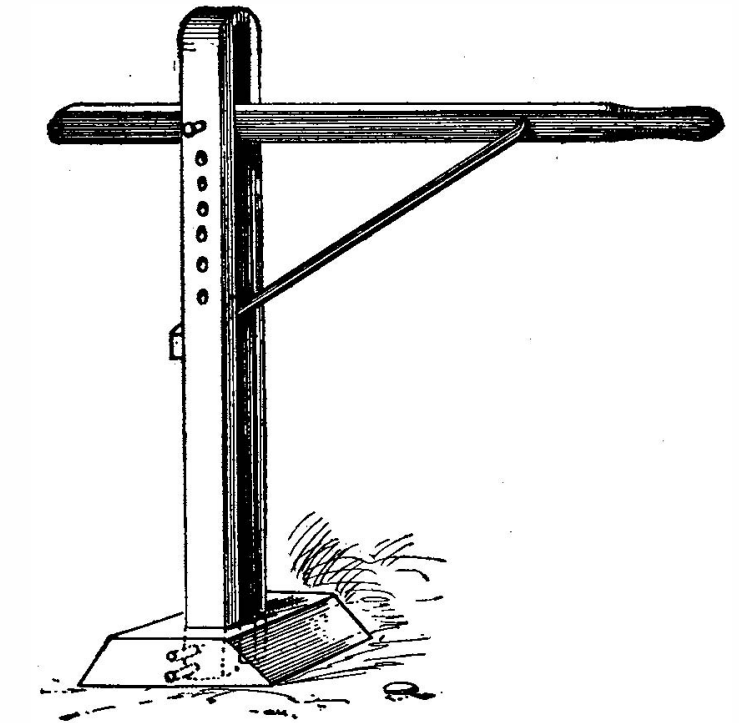

An improvised vehicle jack.

axle is supported is made of strap iron measuring $1 \mathrm{by} 3 / 8$ inch. This is fulcrumed between the uprights by means of a bolt which passes through holes in the sides of the uprights. There are a number of such bolt holes to permit of adjusting the lever to various heights. The weight comes on the short arm of the lever and is lifted by depressing the long arm. To hold the long arm in depressed position a rod is pro vided which is fastened to the lever at one end, while the other end passes between the uprights and is welded to a block of metal. This is adapted to bear against the uprights and serves as a catch to hold the lever at any desired adjustment. The rod shown in the drawing is $3 / 8$ inch in diameter.

\section{Lashing or Seizing Timbers Together By Albert F. Bishop}

TIMBERS from 7 to 10 inches in diameter can be 1 bound together readily with wire about the size of that used in telegraph lines. The end of the wire is turned at right angles and fastened to the timber by a staple. The wire is then wound around the two pieces as tightly as possible from four to six turns. The end of the last turn is bent at right angles and fastened to the other timber by a staple. Now a small pointed bar is inserted in the center of the layers and

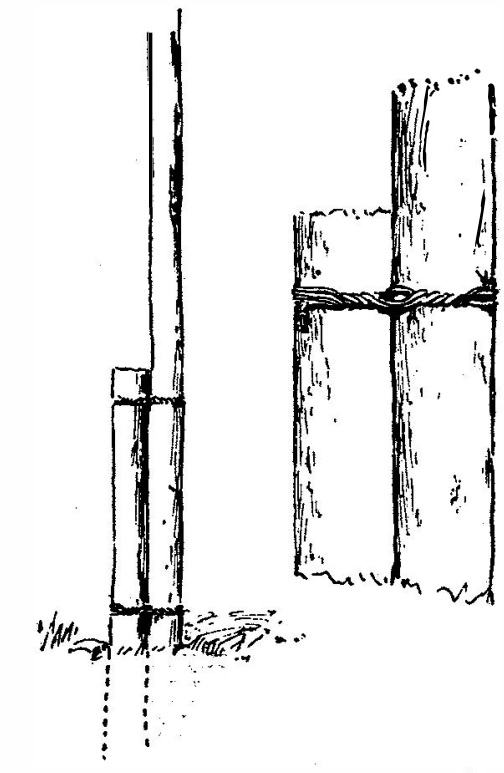

the layers are twisted several times as shown in the sketch. The writer believes two pieces could be bound together in this manner as tightly and firmly as the use of bolts could make them. This method requires very few tools and very slight expense for materials. This wrinkle can be applied to telegraph poles, flag staffs, or repairing fence posts, etc. 